\title{
Intrabronchial stents in heterogenous emphysema: a highly selected material followed 5 years
}

\author{
Gunnar Hillerdal $^{1,2}$, Hirsh Koyi ${ }^{1,2,3,4}$ \\ ${ }^{1}$ Department of Respiratory Medicine, Regional Hospital, Gavle, Sweden; ${ }^{2}$ Department of Respiratory Medicine an Allergy, Karolinska University \\ Hospital, Stockholm, Sweden; ${ }^{3}$ Karolinska Institute, Stockholm, Sweden; ${ }^{4}$ Uppsala University/County Council of Gavleborg, Gavle, Sweden \\ Contributions: (I) Conception and design: G Hillerdal; (II) Administrative support: All authors; (III) Provision of study materials or patients: All \\ authors; (IV) Collection and assembly of data: All authors; (V) Data analysis and interpretation: G Hillerdal; (VI) Manuscript writing: All authors; (VII) \\ Final approval of manuscript: All authors. \\ Correspondence to: Gunnar Hillerdal, MD, FCCP. Department of Respiratory Medicine, Regional Hospital, 80888 Gavle, Sweden. \\ Email gunnar.hillerdal@regiongavleborg.se.
}

\begin{abstract}
Background: Endobronchial lung volume reduction (EBVR) with one-way valves introduced into the most diseased lobe of the lung is a non-invasive method to improve lung function in patients with severe heterogenous emphysema. The problem is to select the right patients for the procedure. Furthermore, the long-term effects have not been reported in most studies.

Methods: EBVR was performed in 35 patients with severely handicapping emphysema and with one radiologically clearly enlarged (at least 125\%) target lung lobe and clearly visible and complete interlobar fissures on CT. Most of the successful survivors have then been followed for five years.

Results: Five (14\%) were primary failures (defined as less than $15 \%$ increase of $\mathrm{FEV}_{1 \text { sec }}$ ) and $10(28 \%$ ) were secondary failures (the valves were coughed up or removed for some reason). In the 21 successful 1 patients, the improvement of $\mathrm{FEV}_{1 \mathrm{sec}}$ was in the mean $59 \%$. Over the years, $\mathrm{FEV}_{1 \text { sec }}$ gradually decreased but was still higher 5 years later than initially. Of the successful group, $76 \%$ were still alive after 5 years, while only $50 \%$ were in the refused or failed groups.

Conclusions: With careful selection of patients remarkably good results in lung function can be achieved, and these improvements will last for years though slowly decrease. In addition, the results indicate an improvement in survival with successful EBVR procedure.
\end{abstract}

Keywords: Emphysema; intrabronchial stents; long-term follow-up; lung function

Submitted Dec 19, 2019. Accepted for publication Jun 08, 2020.

doi: $10.21037 /$ jtd-19-4082

View this article at: http://dx.doi.org/10.21037/jtd-19-4082

\section{Introduction}

Lung volume reduction surgery (LVRS) was initially introduced in 1957 by Brantigan and Mueller, who described it as a reduction pneumoplasty with resection of the most emphysematous parts of the lung (1), but due to complication risks the method never became popular. It was reintroduced in the 1990ies, and a large study published 2003 proved that it could considerably improve lung function and quality of life (2). However, thoracic surgery in patients with very low lung function still carries a risk of morbidity and even mortality. Intrabronchial methods have therefore been developed. One such method is endobronchial lung volume reduction (EBVR), where oneway valves are introduced into all segmental bronchi of the most diseased lobe of the lung, with the goal of making it atelectatic. Earlier studies have shown that in patients with high heterogeneity and complete fissures the results are good, better than any other method except transplantation (3-8). The problem has been to select the right patients for the procedure. Furthermore, the long-term effects have not been reported in most studies. 
At the Lung Department in Karolinska Hospital, Stockholm, Sweden, we started our own small series in 2008, treating only very selected patients fulfilling certain criteria. We now have long-time follow-up of most of these patients. Some of the patients have been partially described earlier $(6,9)$.

We present the following article in accordance with the STROBE reporting checklist (available at http://dx.doi. org/10.21037/jtd-19-4082).

\section{Methods}

\section{Standard criteria}

Patients with severe emphysema causing dyspnoea which considerably affected the quality of life were evaluated for treatment. In addition, these criteria should also be fulfilled: the patient must have stopped smoking at least four months earlier, the residual volume (RV) should be at least $120 \%$, there should be absence of serious other diseases such as malignancy or severe heart disease, bronchiectasis, frequent airway infections (3 or more per year), and prior lung surgery (other than lung transplantation).

\section{Radiological criteria}

To further select the patients a standard CT scan of the thorax was used. The lobe areas on the mid-sagittal view were calculated for each side with the normal program of the CT scanner. This requires clearly visible interlobar fissures, which is also an indication of absence of collateral ventilation. We decided on arbitrary normal values of different lobes in this projection: left lower lobe (LLL) $=50 \%, \mathrm{LUL}=50 \%, \mathrm{RUL}=40 \%, \mathrm{ML}=15 \%$, and $\mathrm{RLL}=45 \%$ (Figure 1). To be accepted for the procedure, the calculated value for the affected lobe should be at least $125 \%$ of the arbitrary value (for the middle lobe, at least 200\%).

Cases were classified as failures if the improvement of $\mathrm{FEV}_{1 \text { sec }}$ was $15 \%$ or less (primary failures), or if the stents were coughed up or had to be removed for some reason (secondary failures).

All patients filled in confirmed assent. The study was approved by the Ethical Committee of the Karolinska Institute (2011-431-31/1). The study was conducted in accordance with the Declaration of Helsinki. The patients were followed until death or failure; however, a few were missed. All patients and also the refused ones were followed by the Swedish population statistics, where if the person has died the date of death can be easily found.

\section{Results}

From 2008 to 2012, 62 patients fulfilled the standard criteria. Of those, 27 did not fulfil the radiological criteria, thus leaving 35 patients who went through the procedure, with in the mean 3 valves (range, 1-4) introduced. Of these, $5(14 \%)$ were primary failures, and $9(28 \%)$ were secondary failures. All but two secondary failures happened within the first 6 months after the procedure; five coughed up one or more stents, and in the other 5 , repeated infections necessitated removal of the stents (Table 1). After removal or coughing up of stents, the $F E V_{1 \text { sec }}$ was very similar to the starting value, with one exception: a man who after repeated infections developed scar tissue in the affected lobe so that it remained atelectatic even after removal of the stents, thus retaining his very improved lung function. Two patients in the successful group had had earlier one-sided lung transplants.

As for other complications, there were no pneumothoraces and only a handful had slight hemoptysis the day after the procedure.

The groups were fairly compatible in their basic values (Table 1).

In the 15 AAT patients, the lower lobes were excluded in all cases but two, where the middle lobe was the target. In the other patients, 11 were in the upper lobes, 3 in the lower lobes, and one in the middle. The improvement of $\mathrm{FEV}_{1 \mathrm{sec}}$ was in the mean 59\% (range, 19-206) in the successful patients, and in those with secondary failure it was $55 \%$ (range, 42-62). Three patients improved more than 100\%, of whom two had lack of alfa-1-trypsin. The lung function of 12 patients who survived 5 years can be seen in Figure 2. In one patient, stents were introduced again on the other side 4 years after placement in the RUL, hence the second improvement (9).

Of the successful group, $76 \%$ were still alive after 5 years, while this figure was only $50 \%$ in the refused or failed groups $(\mathrm{P}<0.01)$.

\section{Discussion}

Of the heavily selected cases in this study, two thirds had an important improvement of their lung function. The emphysematous process continues even after installation of stents, but from a higher level, and most patients were better off for the observed 5 years, and some much more so, 

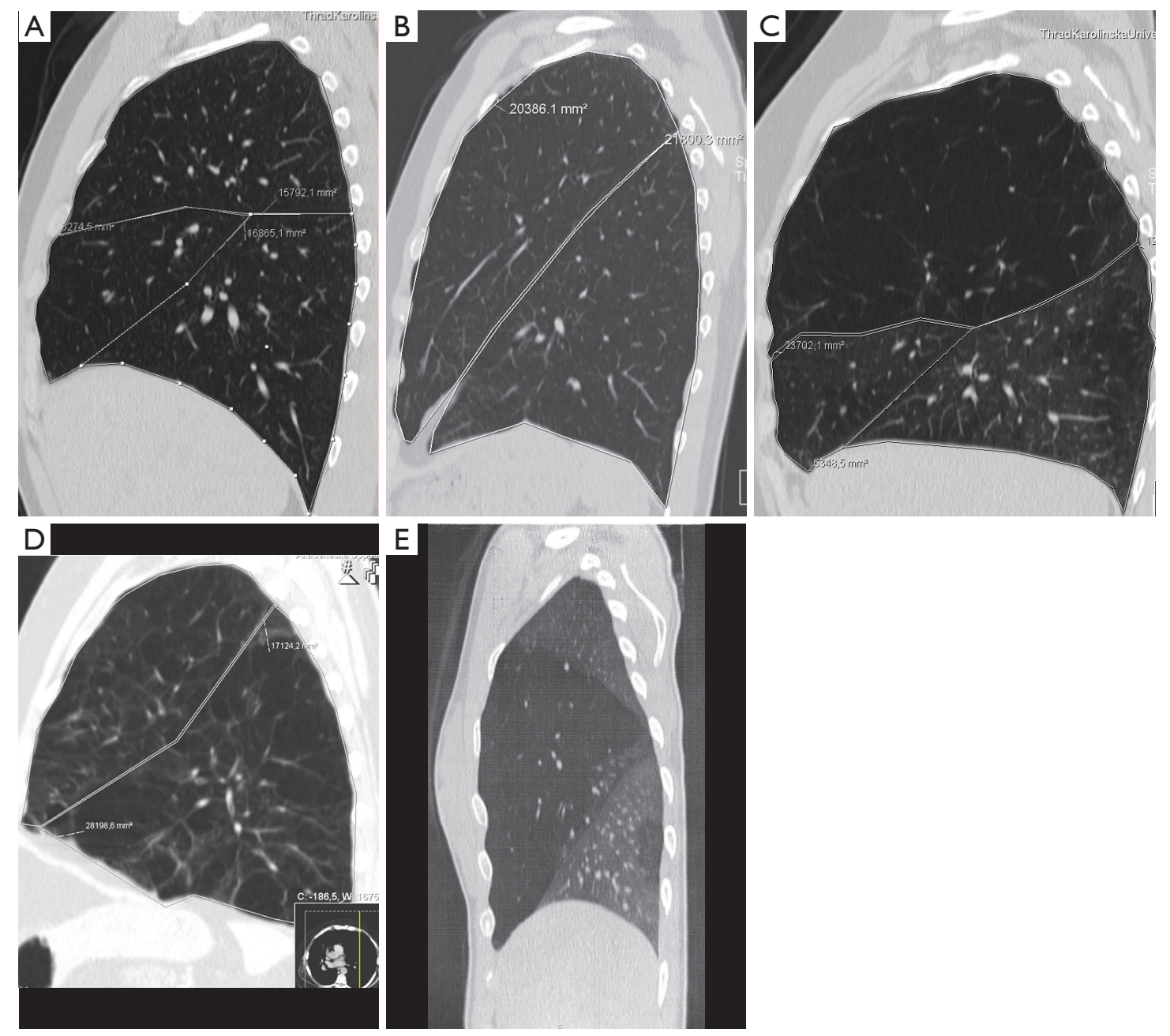

Figure 1 CT scan. (A) Normal, lateral view right lung; (B) normal, lateral view left lung; (C) enlarged right upper lobe; (D) enlarged left lower lobe; (E) enlarged right middle lobe.

Table 1 Basic data

\begin{tabular}{lccccccc}
\hline Group & Number & Male/female & Age, years & Lack of alfa-1-p. & FEV 1 1sec & $\begin{array}{c}\text { FEV } \text { 1sec }_{\text {of }} \text { predicted } \\
\text { Residual volume\% of } \\
\text { predicted }\end{array}$ \\
\hline Successful & 21 & $11 / 10$ & $64.7(49-79)$ & $12(57 \%)$ & $0.83(0.6-1.59)$ & $24.9(18-43)$ & $224(140-309)$ \\
Refused & 27 & $14 / 13$ & $66.9(52-81)$ & $11(41 \%)$ & $0.82(0.27-1,8)$ & $31.0(12-54)$ & $182(120-253)$ \\
Failures & 14 & $12 / 2$ & $70.9(55-85)$ & $5(36 \%)$ & $0.79(0.46-1.3)$ & $24.4(16-53)$ & $221(146-334)$ \\
\hline
\end{tabular}

depending on the level of improvement. The survival curves also indicate that the stents can prolong life. The $50 \%$ survival at 5 years of the non-treated and failure patients illustrates the very poor prognosis of patients with a very low $\mathrm{FEV}_{1 \mathrm{sec}}(10,11)$.

Our radiological approach is based on the physiology of emphysema. In the normal chest, there is a negative pleural pressure due to two balancing forces: the chest wall straining outwards; and the elasticity of the lung striving inwards. In emphysema there is a hyperinflation because of lack of elastic recoil $(1,12,13)$. Consequently, an increased lobe size relative to other lobes indicates a greater loss 


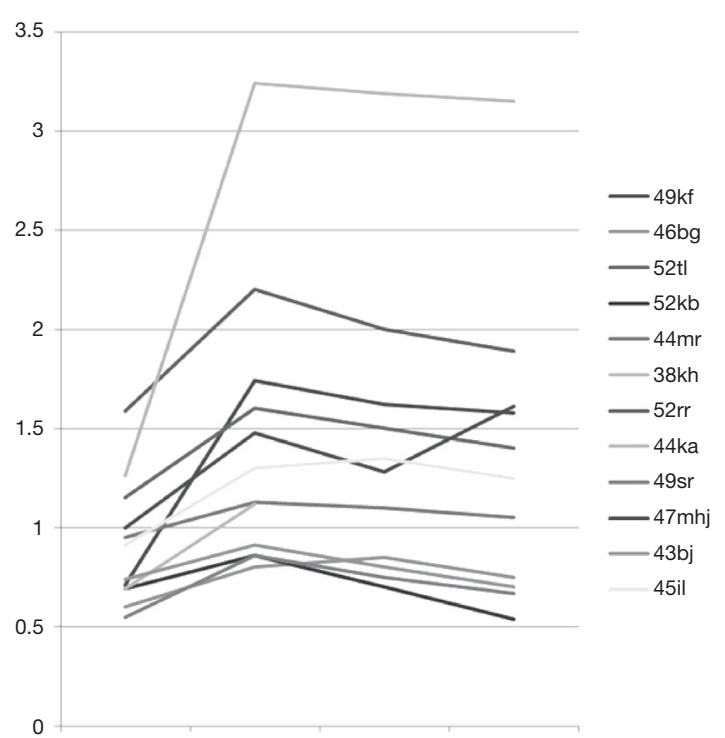

Figure $2 \mathrm{FEV}_{1 \mathrm{sec}}$ in treated patients who survived 5 years.

of elasticity in that lobe than in the other(s), which is a prerequisite for the procedure to work. One caveat with our method: with a marked difference between sides, the mediastinum can be drawn over to the healthier side.

The terminology is confusing: the air in a hyperinflated lobe is called trapped, but the hyperinflation is due to passive distention from the remaining elasticity in the adjacent lobes; healthier parts are described as compressed, when it is its remaining elasticity that contracts it. Thus, in emphysema there is passive hyperinflation, quite different from dynamic hyperinflation of asthma, where small airways are acutely narrowed and the chest wall compression at expiration further diminishes their lumen. Once asthma is treated, the elastic force of the lungs forces the trapped air out; in emphysema there is no such drive. Dynamic hyperinflation occurs in emphysema only at exercise $(13,14)$.

The larger the size difference, the better are the chances of good results. The best results are also seen in cases where there is a complete atelectasis of the target lobe, but most common is a partial atelectasis which can also be functionally very helpful. As seen from Figure 2, it seems that the best results are achieved in patients with a $\mathrm{FEV}_{\text {1sec }}$ of one litre or more. However, even in those with a lower $\mathrm{FEV}_{\text {1sec }}$ there is an improvement which, even if not very impressive figure wise, can make a large difference in quality of life. As seen, one patient went from $\mathrm{FEV}_{\text {1sec }}$ of 0.6 litres to 1.7 , which is going from a very restricted life to one almost normal. Though the patients are few, the findings indicate that one should not wait too long: in suitable patients the best is probably to act when the patient starts complaining of bothersome dyspnoea.

At least some of our primary failures could probably have been avoided had we been able to use the Chartis system, which can verify lack of collateral ventilation (15), but this was not yet available when the study started. The secondary failures are more difficult to avoid.

A fairly high percentage of our patients were AATpatients, which probably mirrors the facts that these patients usually have intact fissures and very often a heterogenous emphysema which mainly affects the lower lobes.

\section{Conclusions}

In conclusion, with careful selection of patients remarkably good results in lung function can be achieved and these improvements will last for years. In addition, the study indicates a better survival with improvement of $\mathrm{FEV} 1_{\text {sec }}$.

\section{Acknowledgments}

Funding: None.

\section{Footnote}

Reporting Checklist: The authors have completed the STROBE reporting checklist. Available at http://dx.doi. org/10.21037/jtd-19-4082

Data Sharing Statement: Available at http://dx.doi. org/10.21037/jtd-19-4082

Conflicts of Interest: Both authors have completed the ICMJE uniform disclosure form (available at http://dx.doi. org/10.21037/jtd-19-4082). The authors have no conflicts of interest to declare.

Ethical Statement: The authors are accountable for all aspects of the work in ensuring that questions related to the accuracy or integrity of any part of the work are appropriately investigated and resolved. All patients filled in confirmed assent. The study was approved by the Ethical Committee of the Karolinska Institute (2011-431$31 / 1)$. The study was conducted in accordance with the Declaration of Helsinki (as revised in 2013).

Open Access Statement: This is an Open Access article distributed in accordance with the Creative Commons 
Attribution-NonCommercial-NoDerivs 4.0 International License (CC BY-NC-ND 4.0), which permits the noncommercial replication and distribution of the article with the strict proviso that no changes or edits are made and the original work is properly cited (including links to both the formal publication through the relevant DOI and the license). See: https://creativecommons.org/licenses/by-nc-nd/4.0/.

\section{References}

1. Brantigan OC, Mueller E. Surgical treatment of pulmonary emphysema. Am Surg 1957;23:789-804.

2. Fishman A, Martinez F, Naunheim K, et al. A randomized trial comparing lung-volume-reduction surgery with medical therapy for severe emphysema. $\mathrm{N}$ Engl J Med 2003;348:2059-73.

3. Davey C, Zoumot Z, Jordan S, et al. Bronchoscopic lung volume reduction with endobronchial valves for patients with heterogeneous emphysema and intact interlobar fissures (the BeLieVeR-HIFi trial): study design and rationale. Thorax 2015;70:288-90.

4. Sciurba FC, Ernst A, Herth FJ, et al. A randomized study of endobronchial valves for advanced emphysema. New Engl J Med 2010;363:1233-44.

5. Venuta F, Anile M, Diso D, et al. Long-term follow-up after bronchoscopic lung volume reduction in patients with emphysema. Eur Respir J 2012:39:1084-9.

6. Hillerdal G, Mindus S. One- to four-year follow-up of endobronchial lung volume reduction in alpha-1antitrypsin deficiency patients: a case series. Respiration 2014;88:320-8.

7. Hopkinson NS, Kemp SV, Toma TP, et al. Atelectasis and

Cite this article as: Hillerdal G, Koyi H. Intrabronchial stents in heterogenous emphysema: a highly selected material followed 5 years. J Thorac Dis 2020;12(7):3524-3528. doi: 10.21037/jtd$19-4082$ survival after bronchoscopic lung volume reduction for COPD. Eur Respir J 2011;37:1346-51.

8. Kemp SV, Slebos DJ, Kirk A, et al. A Multicenter Randomized Controlled Trial of Zephyr Endobronchial Valve Treatment in Heterogeneous Emphysema (TRANSFORM). Am J Respir Crit Care Med 2017;196:1535-43.

9. Hillerdal G. Bilateral endoscopic volume reduction in a woman with severe emphysema. Clin Respir J 2017;11:1091-4.

10. Mannino DM, Doherty DE, Sonia Buist A. Global Initiative on Obstructive Lung Disease (GOLD) classification of lung disease and mortality: findings from the Atherosclerosis Risk in Communities (ARIC) study. Respir Med 2006;100:115-22.

11. Menezes AM, Pérez-Padilla R, Wehrmeister FC, et al. FEV1 is a better predictor of mortality than FVC: the PLATINO cohort study. PLoS One 2014;9:e109732.

12. Morgan MD, Edwards CW, Morris J, et al. Origin and behaviour of emphysematous bullae. Thorax 1989;44:533-8.

13. O'Donnell DE. Hyperinflation, dyspnea, and exercise intolerance in chronic obstructive pulmonary disease. Proc Am Thorac Soc 2006;3:180-4.

14. Satake M, Shioya T, Uemura S, et al. Dynamic hyperinflation and dyspnea during the 6-minute walk test in stable chronic obstructive pulmonary disease patients. Int J Chron Obstruct Pulmon Dis 2015;10:153-8.

15. Shah PL, Herth FJ. Dynamic expiratory airway collapse and evaluation of collateral ventilation with Chartis. Thorax 2014;69:290-1. 